\title{
AÇÕES PRODUTIVAS DA MULHER COMO INCENTIVO À PERMANÊNCIA NO CAMPO: ASSENTAMENTO CAMPINA EM BODOQUENA/MS
}

\author{
Daiane Santana Santos ${ }^{1}$ \\ Ana Paula de Souza Lara² \\ Valter Guimarães ${ }^{3}$
}

\begin{abstract}
RESUMO
A produção agrícola destinada ao atendimento das necessidades do Homem, ou dos Animais, tanto nas propriedades cujos objetivos maiores sejam os da subsistência (como é o caso nos Assentamentos Rurais) ou mesmo nas médias e grandes propriedades (cujo objetivo seja o dos diferentes tipos de comercialização da produção), necessita de solos em condições permanentes de produtividade, porém sempre em busca de perfeita harmonia com as regras da sustentabilidade. Tal produtividade obviamente indica possíveis diferenciações nas formas e intensidade de utilização dos solos, mas é constantemente induzida a recorrer a recursos que cada vez mais melhorem e aumentem a qualidade e quantidade do que se produz. Ainda, num passado recente, cabia ao homem ser o responsável pelo sustento da família, ou seja, produzir renda suficiente para a subsistência. Neste contexto, revela-se o ambiente e nele a necessidade de produzir para sobreviver. No Assentamento Campina em Bodoquena/MS não parecia ser diferente. No entanto, pesquisas revelam que a produção familiar tem mostrado de forma altamente significativa a participação da mulher em praticamente todos os afazeres que antes se pressupunha fossem apenas da competência dos homens. Revelar cenários que identificam a "força de trabalho da mulher" na construção da paisagem nos assentamentos rurais tem sido os objetivos desta pesquisa em andamento.
\end{abstract}

Palavras-chave: Produção Familiar, Assentamentos Rurais, A Mulher no contexto.

\section{ACTIONS PRODUCTION OF WOMAN AS INCENTIVE TO STAY IN THE FIELD : SETTLEMENT IN PLAIN BODOQUENA / MS}

\begin{abstract}
Agricultural production aimed at meeting the needs of man, or of animals, both in properties whose larger goals are those of subsistence (as is the case in rural settlements) or even in medium and large properties (whose goal is the different types of marketing of production), requires permanent conditions of soil productivity, but always in search of perfect harmony with the rules of sustainability. Such productivity obviously indicates possible differentiations in the forms and intensity of land use, but is constantly induced to use features that increasingly improve and increase the quality and
\end{abstract}

\footnotetext{
${ }^{1}$ Graduanda em Geografia Licenciatura. UFMS/CPAq. Bolsista de Iniciação Científica. daianesantanageo@gmail.com

${ }^{2}$ Graduanda em Geografia Bacharelado. UFMS/CPAq. Bolsista Permanência. anapauladesouzalara@gmail.com

${ }^{3}$ Professor Doutor. UFMS/CPAq. vgeovalter@gmail.com
} 
quantity of what is produced. Still, in the recent past, it was to be the man responsible for the sustenance of the family, i.e. producing enough income for subsistence. In this context, it is the environment and the need to produce to survive. At Campina Settlement in Bodoquena/MS does not seem to be different. However, research shows that household production has shown highly significant participation of women in practically all tasks that before were assumed to be only a matter of men. Reveal some paths that identify the "workforce of women" in the construction of the landscape in rural settlements have been the objective of this ongoing research.

Key-words: Family Production, Rural Settlements, Women in context.

\title{
ACCIONES DE PRODUCCIÓN DE LA MUJER COMO INCENTIVO PARA QUEDARSE EN EL CAMPO : SOLUCIÓN EN LLANO BODOQUENA / MS
}

\begin{abstract}
RESUMEN
La producción agrícola orientada a satisfacer las necesidades del hombre, o de animales, tanto en propiedades cuyos objetivos más importantes son las de subsistencia (como es el caso de los asentamientos rurales) o incluso en medianas y grandes propiedades (cuyo objetivo es los diferentes tipos de comercialización de la producción), requiere condiciones permanentes de la productividad del suelo, pero siempre en busca de perfecta armonía con las normas de sostenibilidad. Dicha productividad obviamente indica posibles diferencias en las formas e intensidad de tierra usar, pero constantemente se induce a utilizar las características que mejoran cada vez más y aumentan la calidad y cantidad de lo que se produce. Aún así, en los últimos años, debía ser el hombre responsable para el sustento de la familia, es decir, producir suficientes ingresos para su subsistencia. En este contexto, es el medio ambiente y la necesidad de producir para sobrevivir. En el asentamiento de Campina de Bodoquena/MS no parecen ser diferentes. Sin embargo, las encuestas muestran que la producción doméstica ha mostrado altamente significativa participación de las mujeres en prácticamente todas las empresas que previamente habían sido asumida eran sólo la responsabilidad de los hombres. Revelan escenarios que identifican la "fuerza de trabajo de las mujeres" en la construcción del paisaje en asentamientos rurales han sido los objetivos de esta investigación en curso.
\end{abstract}

Palabras clave: producción doméstica, los asentamientos rurales, la mujer en el contexto.

\section{INTRODUÇÃO}

O município de Bodoquena onde está inserida a área da pesquisa localizase na região sudoeste do estado de Mato Grosso do Sul e tem importância significativa no cenário produtivo nacional, destacando-se as atividades industriais da produção de cimento, calcário, e vem despontando na oferta de produtos turísticos principalmente pelas riquezas das suas belezas naturais. Conforme Guimarães (2013, p.32), "os estudos em Geografia Regional no entendimento da paisagem nas pequenas propriedades, principalmente a da área do Projeto de Assentamento Campina do município de Bodoquena/MS que de inicio revelou problemas de regularização fundiária, traz ainda a falta de estímulo a novas 
investidas no campo da produtividade, mas principalmente os perigos da ocupação das encostas do relevo serrano".

É, neste cenário ambiental, que famílias de acampados foram assentadas em projetos coordenados pelo Instituto Nacional de Reforma Agrária (INCRA). As dificuldades na lida diária pela subsistência das famílias tem incluído de forma representativa a participação da mulher também nas atividades rurais, revelando ações significativas na permanência das famílias no campo. Por outro lado, nos eventos científicos que tratam de questões ligadas a gênero, sexualidade, direitos, cidadania e outros, há que se considerar o que vem sendo discutido a respeito e, nesse trabalho foram objeto de revisão bibliográfica algumas publicações interessantes, permitindo enxergar, sob outro prisma a mulher zelando pelo seu patrimônio.

\section{OBJETIVOS}

Os objetivos da investigação caminharam na busca do conhecimento do "lugar" obtendo-se resultados que revelam sua dinâmica natural, social e econômica, com similaridades no campo produtivo de subsistência familiar. O contato com os moradores objetivou revelar a importância da mulher exercendo influência direta no contexto produtivo familiar, buscando contribuir para a redução dos casos de êxodo rural. Por fim objetivou-se mostrar que as ações da mulher nas atividades rurais tem sido de grande valia na permanência das famílias no campo.

\section{CONCEPÇÕES TEÓRICO METODOLÓGICAS}

Conforme afirmam Nascimento e Rosa (2014), a mulher necessariamente, em sua lida no habitat rural exerce funções duplas dominando a responsabilidade doméstica seguida de disponibilidades para ajudar nas tarefas rurais. Ao tratarem da questão da mulher na luta pela permanência na terra questionam os enfoquem duvidosos de "gênero e/ou classe?". No entanto dizem que ela exercendo a luta pelo seu direito acaba cumprindo uma jornada tripla de atividades. Nas considerações 
finais estes autores nada concluem como contribuição à permanência na terra. Apenas enfatizam questões de emancipação de classe, quando nada foi discutido da importância da participação da mulher nas tarefas rurais como luta em defesa da produção de alimentos.

Quanto à concepção da mulher assentada em termos de diferenciação de gênero, Pageú (2014) considera a importância do papel da mulher nos movimentos pela conquista da terra, bem como mostrar posicionamentos relacionados à submissão no mundo atual. Relata que mulheres rurais auxiliam "no plantio e na colheita", mas que predomina a responsabilidade doméstica considerada como "limpeza do terreiro, limpeza da casa, debulhar o arroz, o milho e o feijão para as refeições...", deixando de fazer referência à participação da mulher nas tarefas rurais, ou seja, é como se quisesse comparar certos serviços domésticos urbanos como escolher arroz, feijão, e outros cujo trabalho difere em muito quando executados no meio rural. Portanto exercem sim, além do plantio e da colheita outros serviços típicos do ambiente rural. Ao concluir, Pageú (2014) deixa claro que nas decisões finais relacionadas a unidade familiar a mulher não tem voz ativa e que isto pode pesar negativamente quanto a questões de direitos à terra. Como se trata de resultado de pesquisa especifica de um único ambiente rural, o assentamento 10 de Abril entende-se que tal fato não deva ser generalizado.

SCHAEFER, GÓES e OLIVEIRA (2014) manifestam pontos de vista conclusivos sobre impactos de renda do programa bolsa família no cotidiano rural das mulheres do assentamento Joana D'Arc III em Porto Velho. Nos resultados e discussões enfatizam que as mulheres assumem os afazeres domésticos, o trabalho no campo e também o dos aproveitamentos/confecção de doces, queijos manteigas e outros. Estes autores concluíram que as rendas recebidas dos governos não são motivações para o abandono das tarefas auxiliares no meio rural. Parece coerente mostrar a importância e o significado das mulheres como força ativa nos destinos da propriedade rural.

Segundo afirma Del Priore (1998), apud Costa Silva et al (2002) p. 7, na Filosofia a diferença sobre as quais todas as outras diferenças se expressam e se fabricam é a diferença de sexos. Dela pode se dizer, derivam os efeitos sobre a divisão do trabalho entre homem e mulher, mesmo depois do surgimento do 
conceito de igualdade no final do século XVIII. Fica evidente a sustentação das relações de poder no espaço e tempo, conforme destaca Silva (2004) quando se refere ao fato de que homens e mulheres sempre se relacionaram em diferentes períodos históricos. Deixa evidente o "crescimento" da mulher quando se insere em espaços, profissões, campos político-sociais que como é do conhecimento de todos, espaços do domínio masculino.

Ainda num passado recente cabia ao homem ser o responsável pelo sustento da família, ou seja, produzir renda suficiente para a subsistência. O poder do homem exercia influencias diretas sobre os afazeres de suposta responsabilidade da mulher tais como: serviços domésticos (cuidar da casa, da roupa, da comida), cuidar dos filhos (alimentação, educação familiar, encaminhamentos escolares que incluem as tarefas extraclasses, incluindo-se aqui também as questões de saúde como acompanhar/levar filhos para atendimento médico, campanhas de vacinações e outros), onde a participação do homem estava representada pelos custos financeiros de algumas dessas "responsabilidades" da mulher. Silva (2004), se referenciando a Cope (2002), reforça a supremacia dos papéis exercidos pelos homens deixando claro que oportunidades e privilégios estavam fechados às mulheres. Em suas considerações finais Silva (2004) reforça que estudos do gênero na Geografia devem considerar "questões sobre trabalho, produção e reprodução e a divisão do trabalho, além do papel da mulher na construção da cultura e da natureza".

No desenvolvimento desta pesquisa, alguns resultados já foram objeto de divulgação enfatizando a importância do lugar como forma de convivência harmoniosa da "produção familiar com a natureza".

Dos procedimentos metodológicos aplicados em etapas anteriores, foi possível obter informações das condições socioeconômicas dos assentados, cujos contatos permitiram melhor aceitação do nosso grupo de pesquisa quando da obtenção de dados que contribuíram para revelação parcial dos resultados nesse artigo.

Para tanto mantivemos como procedimento visitas às propriedades rurais com o intuito de "bater um papo" apenas com as mulheres e delas conseguir 
compreender as ações femininas na organização dos ambientes paisagísticos da produção e sustentação da produção familiar.

\section{RESULTADOS E DISCUSSÕES}

Todas essas indagações nos remetem para o artigo de autoria de Ribeiro e Gama, 2014, quando buscam mostrar a necessidade das mulheres rurais conquistarem "direitos da cidadania, da igualdade de gênero". Consideram não haver direitos quanto à propriedade conjunta da terra, o que também inviabiliza ações da mulher em conquistar linhas de créditos rurais. Ainda esses autores falam de violência contra as mulheres, mas não deixam claro esse entendimento.

Entende-se que há muitos artigos científicos que priorizam a discussão de temáticas relacionadas a fatos negativos, generalizando qualquer trabalho fora das "lides domésticas" quando, por exemplo, a mulher sai em busca de auxiliar nas tarefas do meio rural, chamando a atenção para questões de direitos, cidadania e outros, mas não se preocupam em enxergar as causas que originaram ações de compartilhamento das tarefas do homem pela mulher.

A Geografia, como ciência das organizações espaciais, tem estado presente cientificamente na contribuição à busca de soluções para os problemas presentes na superfície da Terra. A questão das formas de utilização da terra em áreas rurais, principalmente agrícola, parecia única a estar à frente dos resultados diagnosticados até então, relacionados à probabilidade do surgimento de situações que podem colocar em risco a sustentabilidade do ambiente. No assentamento Campina, antecedendo às entrevistas com as mulheres, a equipe de pesquisa conseguiu resultados no campo socioeconômico e ambiental, figuras 01 a 08.

Por outro lado das informações obtidas há também resultados que ora contribui, ora podem se tornar motivos de preocupação aos moradores. Pelo menos em mais de $50 \%$ das propriedades não há apoio do governo com relação a recursos provenientes dos diferentes tipos de ajuda financeira, fator que se soma a uma problemática que vem se arrastando desde o inicio do processo de ocupação dos lotes que é o da dívida pra com o INCRA, pois cada propriedade é ciente de que a terra não foi cedida gratuitamente e do debito continua pendente naquele Órgão. Ainda considera-se o benefício do abastecimento de água encanada oriunda de 


\section{Campo, Agronegócio}

e as Práticas Sustentáveis

poços semi-artesianos, condição que é muito valorizada e necessária atualmente para que as famílias lá permaneçam principalmente as dos lotes não beneficiados com águas fluviais. A maioria das propriedades não possui poço comum, uma vez que estão assentadas sobre terrenos calcários afetados por orogenia de dobras assimétricas fragilizando a disponibilidade de reservas de águas e sustentação do nível do lençol freático a baixa profundidade.

Figura 1 - Usos do solo no Assentamento Campina/MS a partir de registros fotográficos.

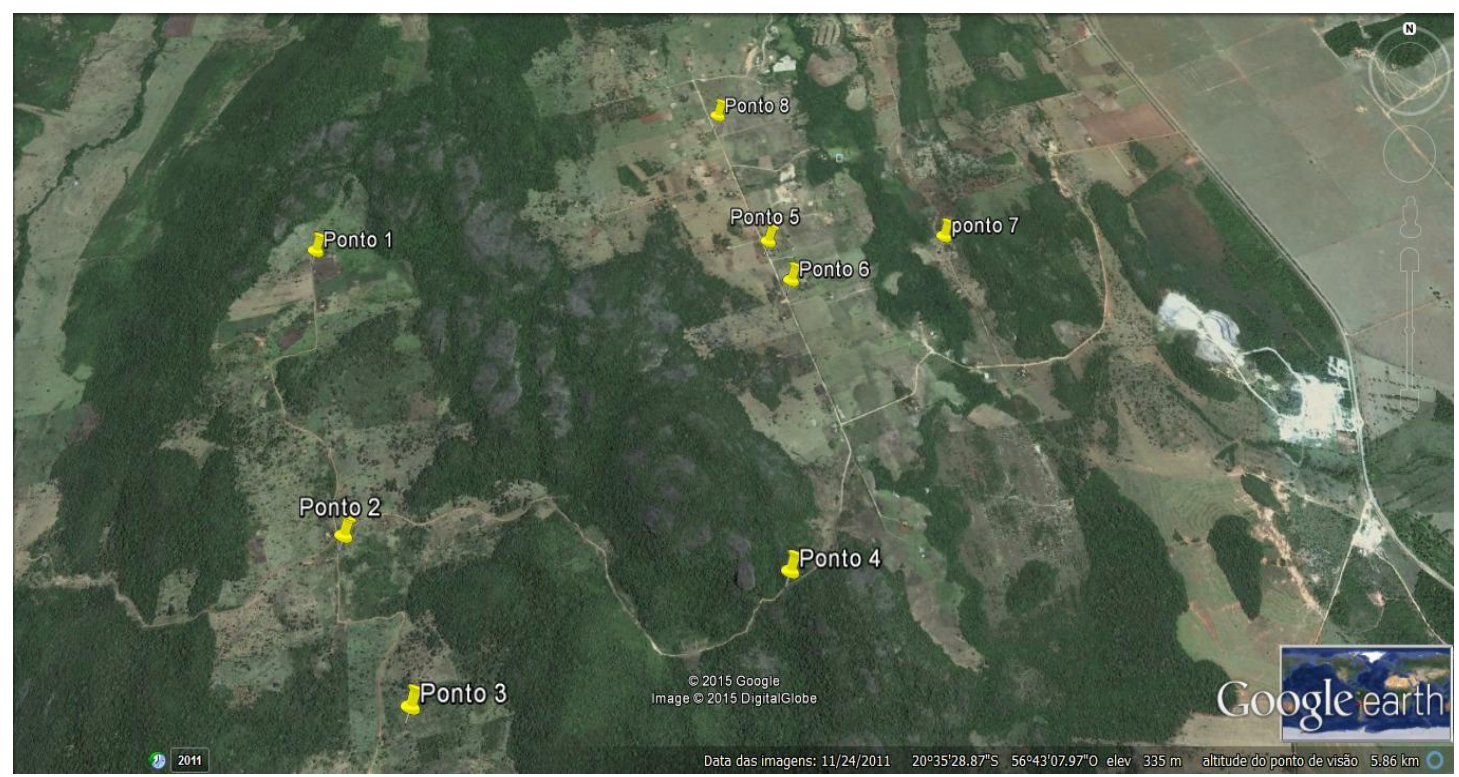

Fonte: Plotagem em imagem orbital Google Earth-acessado em maio/2015. 


\section{Campo, Agronegócio}

e as Práticas Sustentáveis

Figura 2 - Lote da Dona Raimunda. Solo utilizado com mandiocal (recém-plantado e em consumo) e frutíferas.

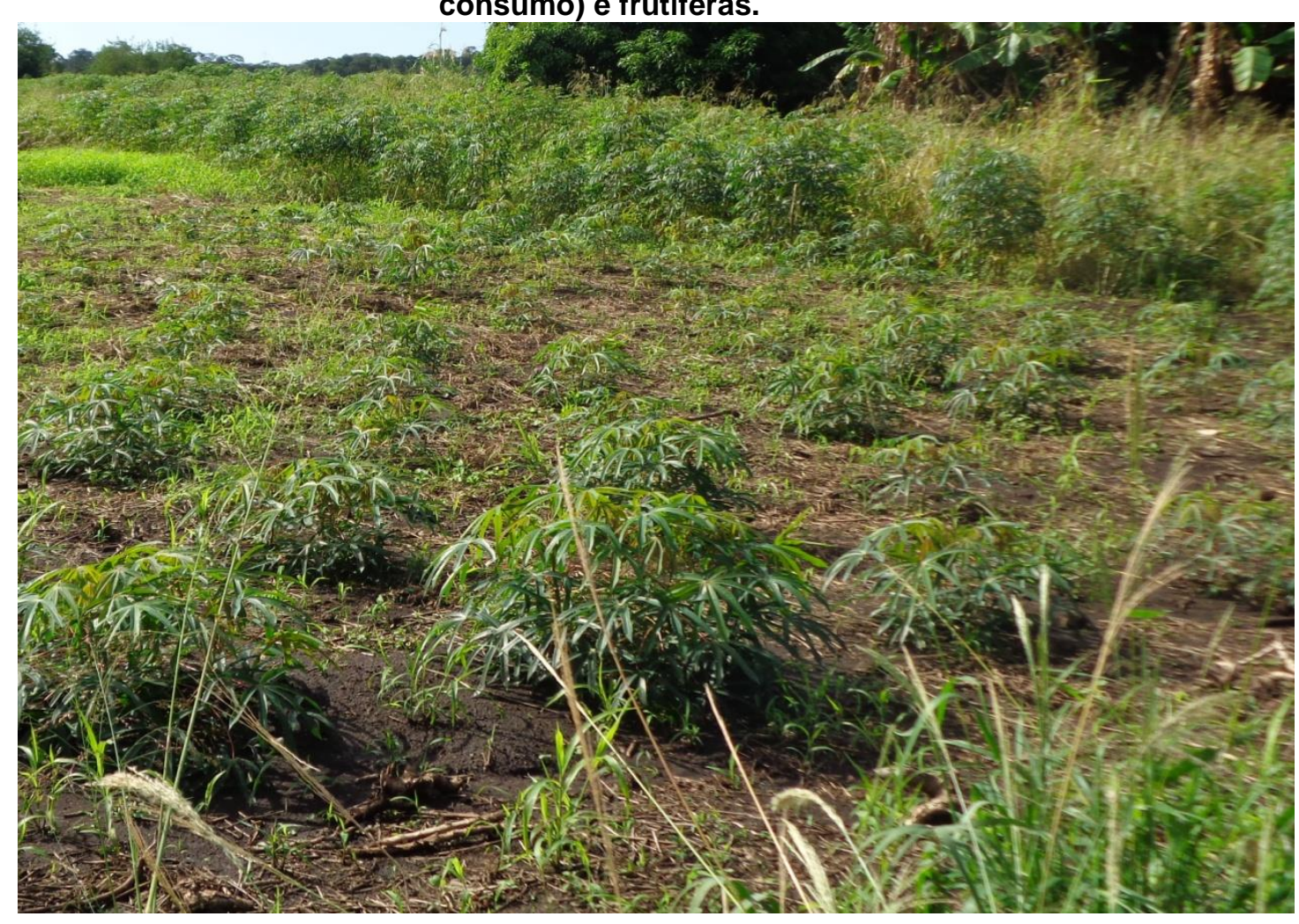

Fonte: Pesquisa a campo Maio de 2015.

Figura 3 - Lote do Bonfim. Área plantada com milho, próximo de colheita, vendo-se ao fundo área de reserva legal coletiva.

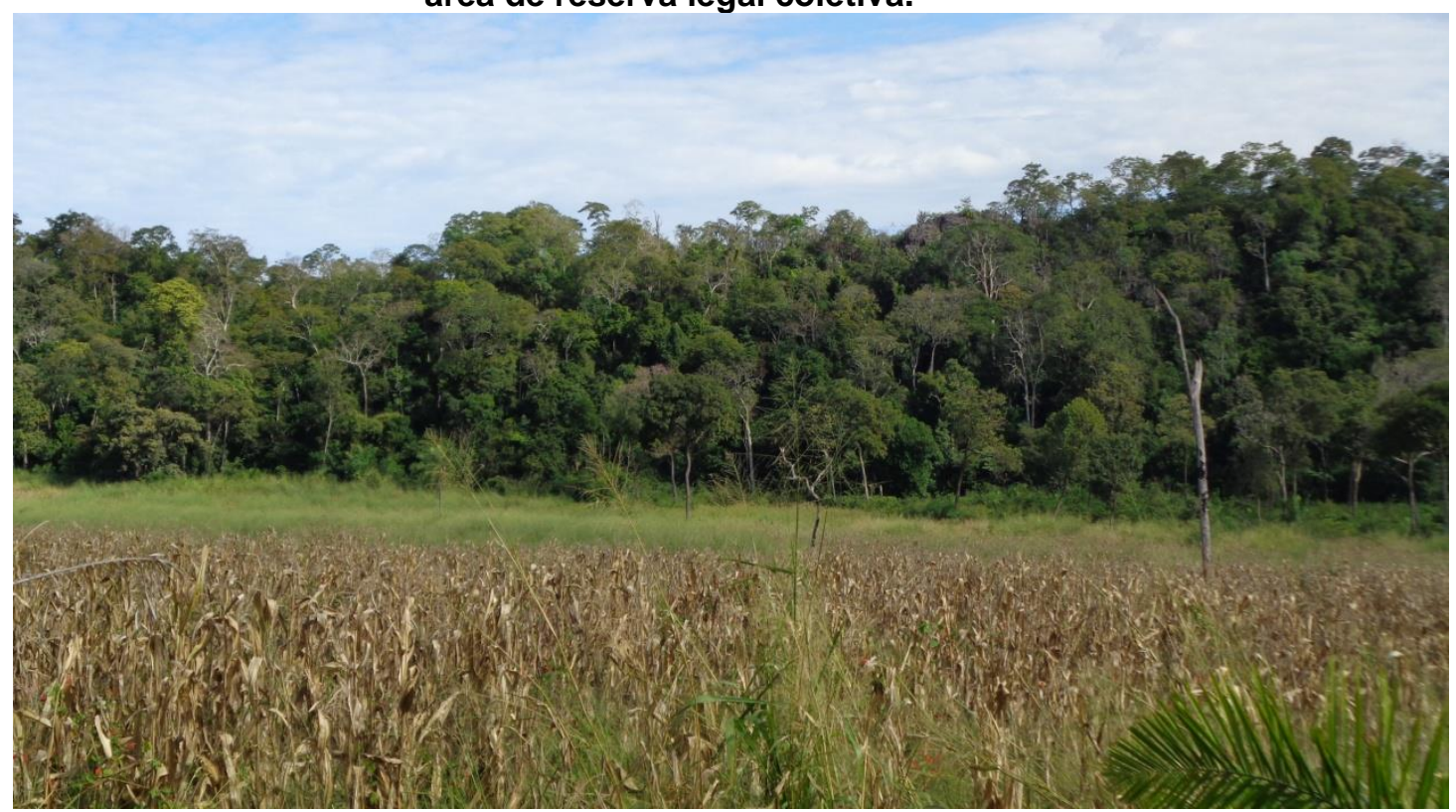

Fonte: Pesquisa a campo Maio de 2015. 


\section{Fórum Ambiental}

da Alta Paulista

Volume 11, Número 02, 2015

Campo, Agronegócio

e as Práticas Sustentáveis

Figura 4 - Sítio do Orlando. Área de fundo de vale utilizada para diversos plantios, como hortaliças de consumo familiar e de comercialização na feira semanal aos sábados em Bodoquena-MS.

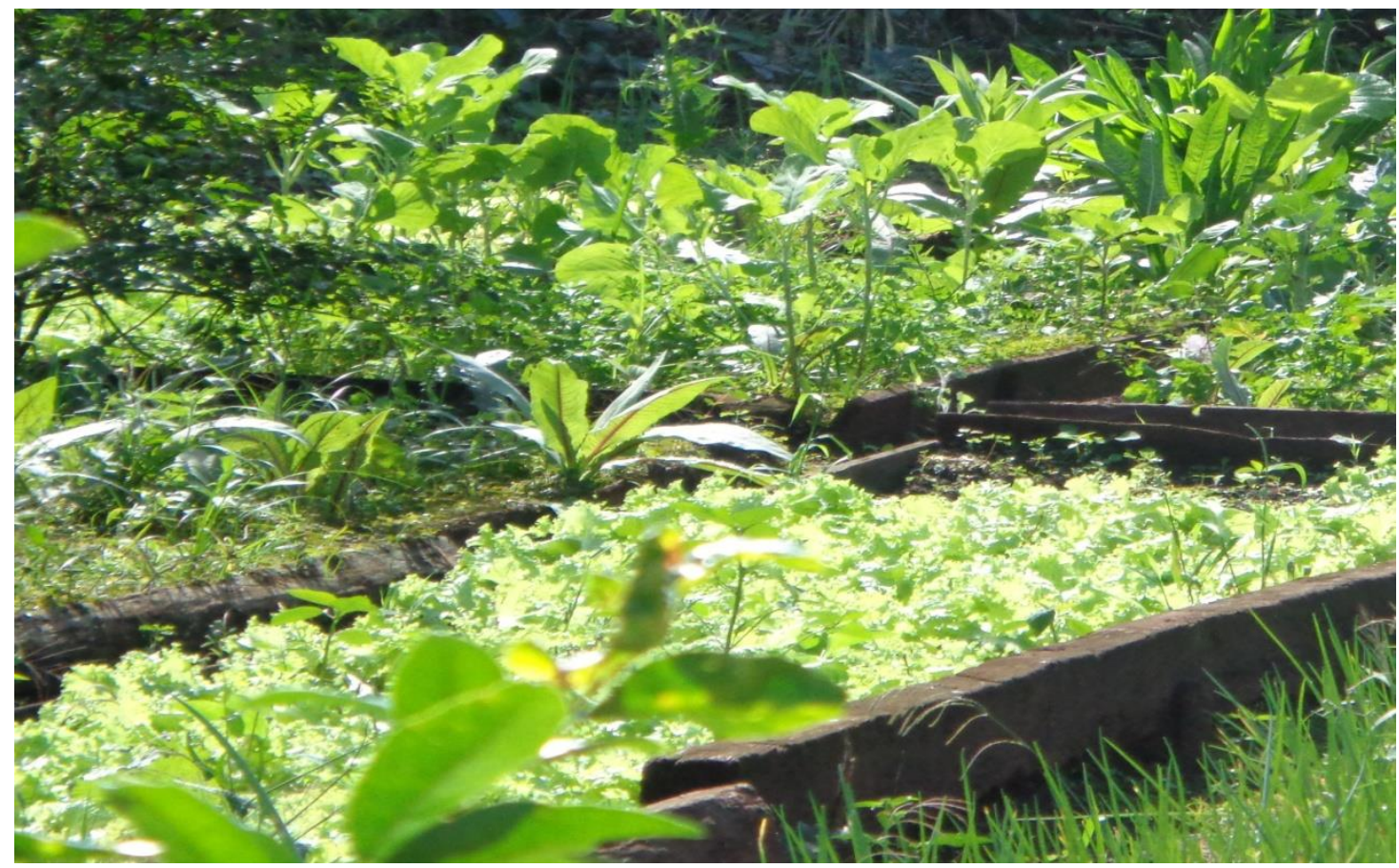

Fonte: Pesquisa a campo Maio de 2015.

Figura 5 - Lote nas proximidades do Orlando. Fato comum também nas demais propriedades é a criação de galinhas, entendida por alguns como uma tarefa doméstica.

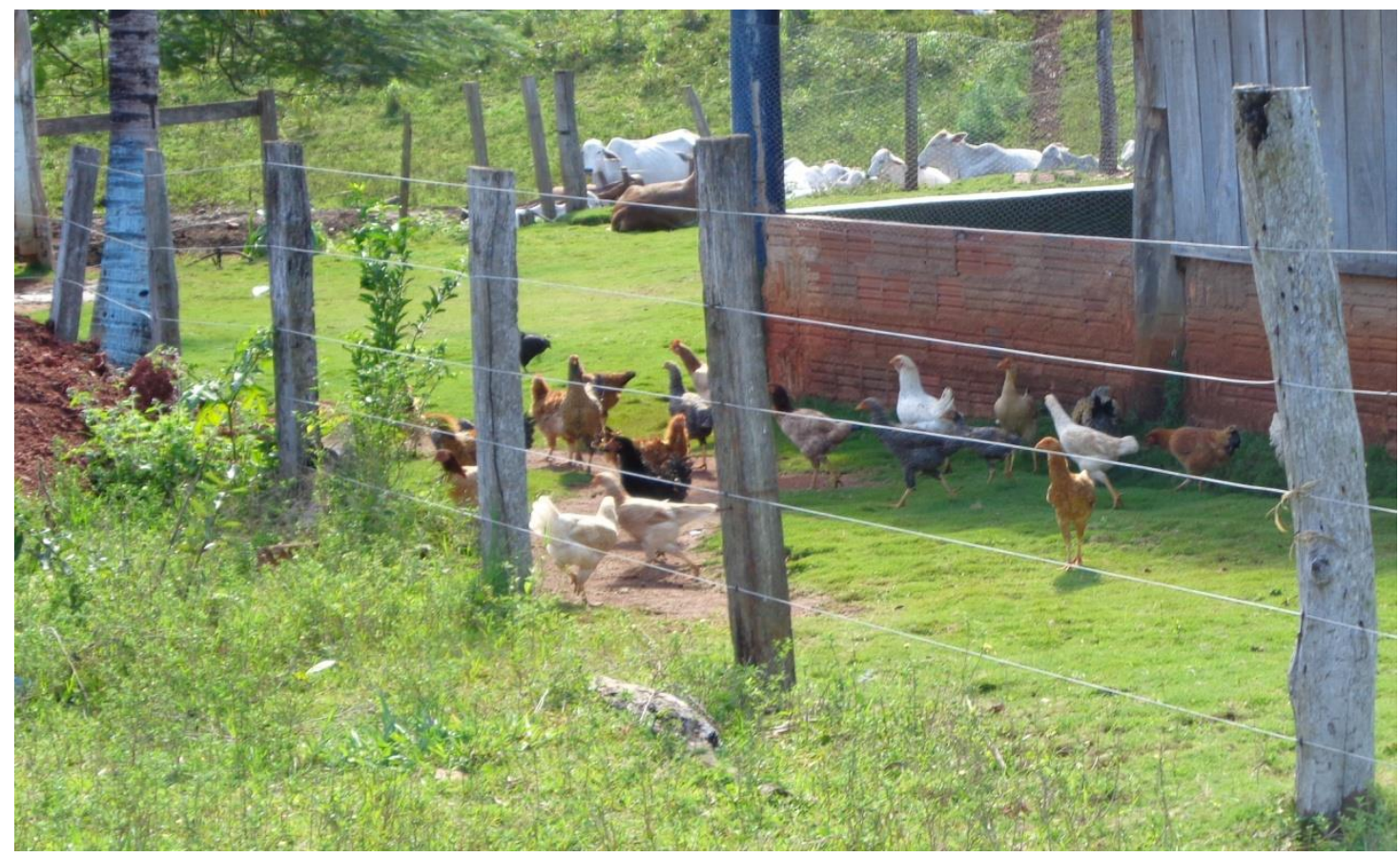

Fonte: Pesquisa a campo Maio de 2015. 
Figura 6 - Sítio do Garrucha. Hortaliças para consumo e principalmente para comercialização utilizando meios de produção mais seguros (proteção e irrigação).

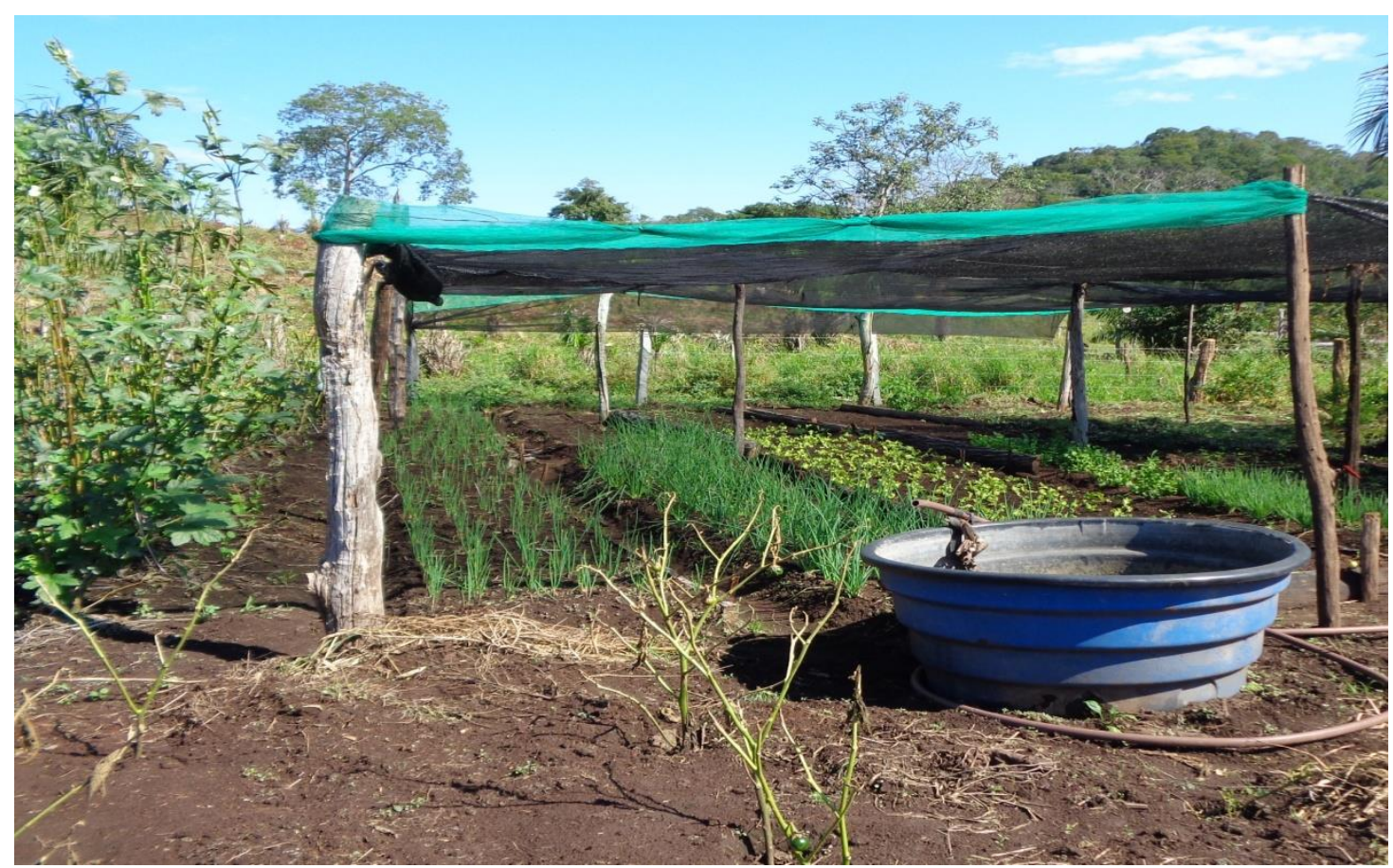

Fonte: Pesquisa a campo Maio de 2015.

Figura 7 - Proximidade do sítio do Odair. Roça de feijão, aparentemente para consumo familiar, entremeados com o quiabo, uma planta arbustivas de produção anual.

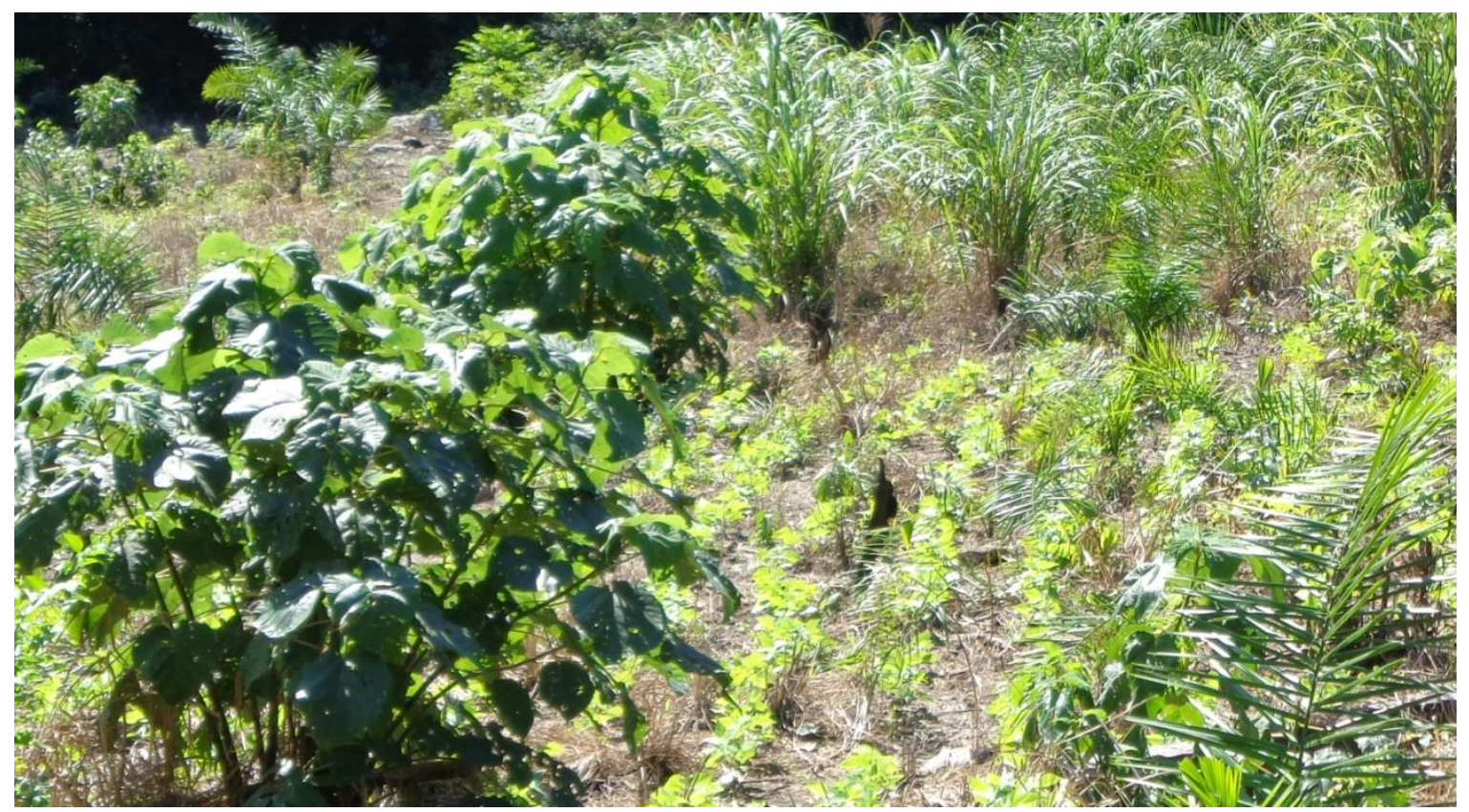

Fonte: Pesquisa a campo Maio de 2015. 
Figura 8 - Lote nas proximidades da escola municipal. Exemplo de produção de verduras voltadas para comercialização principalmente. O local é bastante próximo da cidade de Bodoquena-MS onde se realiza a chamada feirinha aos sábados.

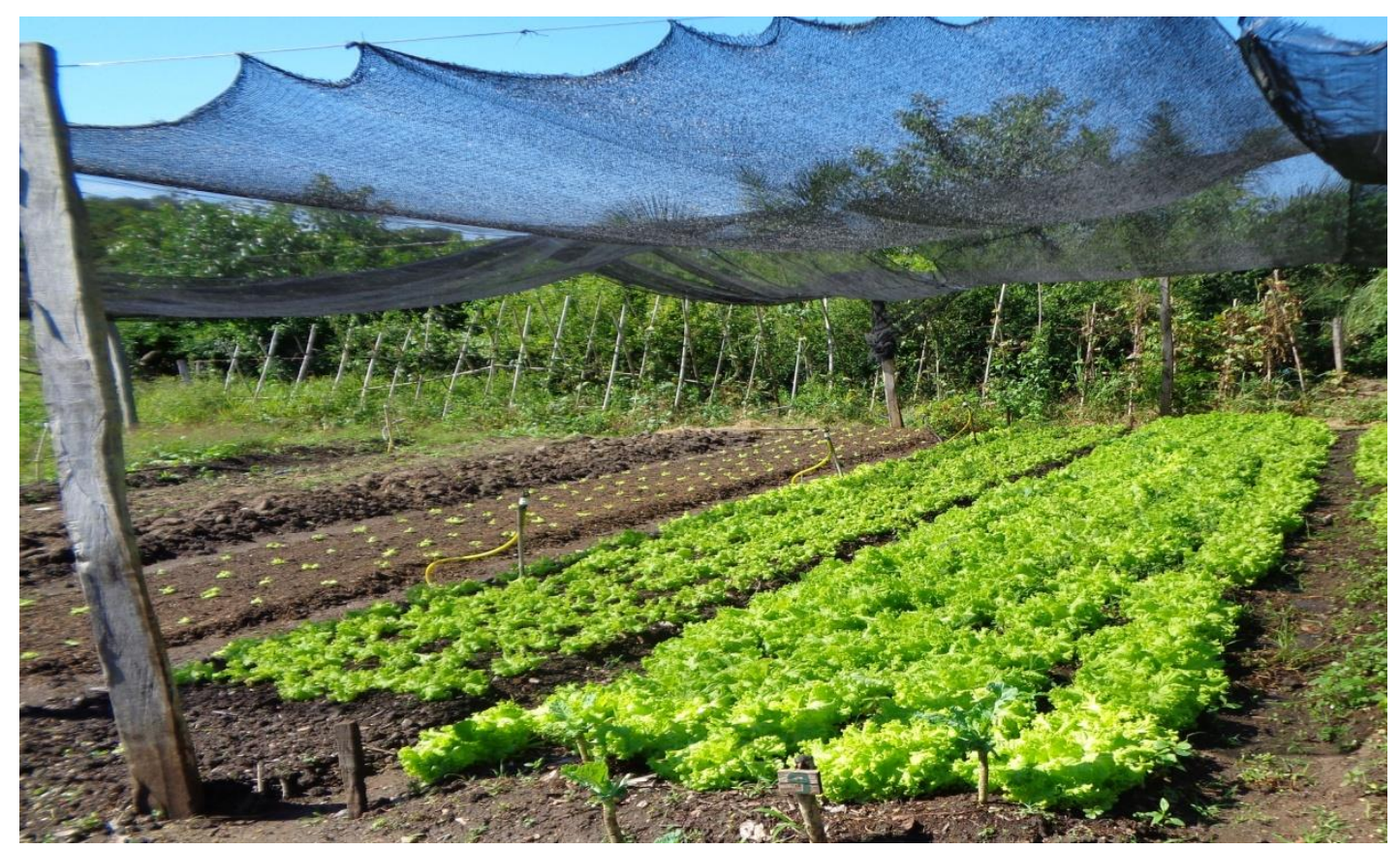

Fonte: Pesquisa a campo Maio de 2015.

\section{CONCLUSÃO}

Das publicações aqui elencadas, a maioria discutindo questões de cidadania e direitos das mulheres, chega-se a diversas indagações que permitem concluir que nas tarefas familiares, no assentamento Campina, à medida que os filhos abandonam o habitat alegando a busca de melhores condições de vida, elas têm tido participação mais significativa. No entanto, entende-se que naqueles ambientes, na ausência ou não dos filhos, apenas participam conjuntamente da produção familiar e que em relação a tais ações não estão "perdendo" seus direitos de cidadania quando contribuem no fazer rural, como exemplos aqui representados nas fotografias documentais.

É sabido que sem infraestrutura adequada, muitos assentados, especialmente aqueles interessados em permanecer no ambiente rural, acabam por empurrar para frente suas "propriedades", isto depois dos filhos já terem ido à frente à busca de oportunidades melhores. Mesmo assim, outra significativa parcela de famílias ainda faz do ambiente rural sua morada. Isto pode ser sentido nos 
resultados das conversas informais com as mulheres quando estas manifestam, na sua maioria, com orgulho, a satisfação em estarem presentes no dia-a-dia das tarefas do lar, da roça (como dizem), tentando contribuir com a sustentabilidade das relações familiares, da produção familiar, da harmonização do lugar.

\section{REFERÊNCIAS}

ARAUJO DA SILVA, Karina; GUIMARÃES, Valter. "Assentamento Campina: a organização espacial em cenários de transformação". Expansão e Produção rural X Sustentabilidade. IX Forum Ambiental da Alta Paulista. v. 9, n. 7, p.80-91. Tupã, 2013.

COSTA SILVA, Evaldo Souza da; ARAUJO, Ana Paula. FACINCANI, Edna Maria. Mulher e Violência. Revista Pantaneira. v. 3, n.2, p.07-16. Editora UFMS. Campo Grande, 2002.

GUIMARÃES, Valter. Assentamento Campina em Bodoquena/MS: O Lugar (Ambiente) em suas relações Socioeconômicas. Revista Pantaneira. v. 15, p. 31 a 38. Editora UFMS. Campo Grande, 2013.

NASCIMENTO, Aline Cristina; ROSA, Marcelo do Nascimento. A Mulher na luta pela permanência na terra: uma questão de gênero e/ou classe? Anais do II Seminário Latino Americano de Geografia, Gênero e Sexualidades. p.784-797. UFRO/Departamento de Geografia. Porto Velho, 2014.

PAGEÚ, Ohana Alencar. Assentamento 10 de abril, Crato-CE, Concepção da mulher assentada na perspectiva de diferenciação de gênero. Anais do II Seminário Latino Americano de Geografia, Gênero e Sexualidades. p.1443-1457. UFRO/Departamento de Geografia. Porto Velho, 2014.

RIBEIRO, Alyson Alves; GAMA, Andrea Nogueira; MOREIRA, Maria Consuelo. As Mulheres em Movimento: o MMTR, O MMC e a marcha das margaridas na luta contra a pobreza, expropriação e violência no campo. Anais do II Seminário Latino Americano de Geografia, Gênero e Sexualidades. p. 798-812. UFRO/Departamento de Geografia. Porto Velho, 2014.

SCHAEFER, Ana Paula Bezerra; GÓES, Kelyany Oliveira Castro de; OLIVEIRA, Gicely Cardoso de. Os Impactos do programa de transferência de renda do bolsa família na vida das mulheres rurais do assentamento rural Joana D'Arc III. Anais do II Seminário Latino Americano de Geografia, Gênero e Sexualidades. p. 854-870UFRO/Departamento de Geografia. Porto Velho, 2014.

SILVA, Christian Nunes da. Geografia e Gênero: Um estudo necessário. Revista de Geografia. n. 19, p. 53-58. DG/UEL. Londrina, 2004. 